\title{
Internet Plus Agriculture Mode
}

\author{
Xi Chen*
}

\author{
Ningbo Hanvos-Kent School, Ningbo, 315202, China \\ Corresponding Author's Email:911235591@qq.com
}

\begin{abstract}
Under the historical development of agriculture at China and abroad and the development of Internet at home and abroad, agriculture has spawned a different agriculture business model from the past. This model will help alleviate the public's requirements for food. The application of new technologies to agriculture will carry out a new reform of the agricultural model, in addition to reducing the cost of labour and time, more importantly, the application of new technology is bound to improve the quality of products.
\end{abstract}

Keywords: agricultural economy, agricultural mode, Internet plus

\section{INTRODUCTION}

In the past decade, the change of China's agricultural model will have a strong positive impact on society and economy. Only true and reliable information can help the public understand the different decision-making information between modern Chinese agriculture and Chinese agriculture in the old era, and how much progress China has made compared with foreign countries in recent years. The falsity of the network may lead to the collapse of the whole system. At present, China's agricultural model is mainly self-produced and self-sold. With the development of science and technology, the rational application of new technology is bound to help agriculture carry out a more scientific and effective sales mode, create a new agricultural model system and improve farmers' living conditions.

\section{INTERNET DEVELOPMENT}

\subsection{Internet history international history}

\subsection{1. computer development history}

Referring to the development of computer, people have to mention Mr. Turing's contribution to computer. As early as 1945, Mr. Turing put forward the concept of computer, and then used various methods to study computer logic design and specific work. Soon after, the first electronic computer was born at the University of Pennsylvania. People call it ENIAC, that is, ENIAC. Its birth marks people's march towards the electronic information age. People have also assigned to the computer age. There are four stages. The first stage is the era of electronic tube computer. The main logic device of this generation of computer is electronic tube, which uses machine language programming, and then assembly language. The second stage is the era of transistor computer. The main logic device of this generation of computer is transistor. Management program and high-level programming language have appeared. Its main application scope is data processing, automatic control and so on. The third stage is the computer age of small and medium-sized integrated circuits. The main logic devices of this generation of computers are medium and small-scale integrated circuits. At this time, high-level languages such as operating system and diagnostic program basic have appeared. The main applications are scientific computing, data processing, transaction management, industrial control and other fields. The fourth stage is the era of large-scale integrated circuit computer. The main logic devices of this generation of computers are large-scale and super large-scale integrated circuits and microprocessor chips. Due to the fast operation speed, large storage capacity, and the integration of computer technology with network technology and communication technology, computer software has developed by leaps and bounds Database technology and various application software came into real life. ${ }^{[1]}$

\subsection{2. history of Internet development at international}

The early development of the Internet originated from the struggle between the United States and the Soviet Union. In the early stage, because the Soviet 
Union first launched satellites into space, the United States accelerated the research and development of satellites for the purpose of self-defence. It led to the formation of the prototype of the Internet, and then American universities began to develop its military role. The early prototype was an experimental network composed of computers from MIT's Lincoln Laboratory and the system development company in Santa Monica, California. So far, the foundation of the network has been set, and since then, the Internet has entered the development stage. Many universities and laboratories have formed networks for experiments. Soon, the United States began to hold a conference to discuss how to build the network. This network will connect several universities and laboratories. The Internet will soon be developed into new uses, such as sending e-mail, listing letters, selectively reading, transferring files, forwarding, and replying. Since then, the Internet is not only the network of the United States, it began to spread all over the world. It has laid the foundation for the future global village. However, with the growth of the Internet, many people who try to do something wrong are also ready to move. After the first attack and attack, the world gradually began to pay attention to protecting their network security. After the launch of the world wide web, it provides people with connections of different information. The community began to connect directly to the Internet, which is a big commercial step. People can even order pizza online. Since then, the Internet has entered the era of rapid development, and a large number of Internet related information have poured in. Many Internets related services are also gradually open to the public, such as e-mail and ephone. Many functions are facing the public. The United States is no longer the only country with the Internet. One after another, many countries began to develop the Internet. The birth of the first iPhone marks mankind's march towards the mobile Internet. It is very important for AI innovation. Since 2010, AI has been integrated into our daily life. We use smart phones with voice assistants and computers with "smart" functions, which most of us take for granted. Artificial intelligence is no longer a daydream, and it has been for some time. Apple released Siri intelligent voice, and Google deep mind launched AlphaGo, beating all go champions. Since then, artificial intelligence may continue to evolve, such as automatic driving and machine learning ability. In recent years, blockchain technology has been paid more and more attention because of bitcoin. Blockchain originated from bitcoin. The architecture concept of e-cash system based on P2P network technology, encryption technology, blockchain technology, etc. marks the birth of bitcoin. Two months later, the theory came into practice, and the first creation block with serial number 0 was born on January 3, 2009. A few days later, on January 9, 2009, the block with serial number 1 appeared and connected with the creation block with serial number 0 to form a chain, marking the birth of the blockchain. ${ }^{[2]}$

\subsection{Development of Internet in China}

Next, it is about the development history of the domestic Internet. The development history of China's Internet can be roughly divided into three stages. The first is the introduction of the Internet. In April 1994, NCFC took the lead in directly connecting with the American NSFNET, realizing the full functional network connection between China and the Internet, marking the birth of China's earliest international Internet. China Science and technology network has become the earliest international Internet in China. But after that, China was still in the initial stage of Internet research and development. Therefore, this technology has not been popularized to the masses for the first time. After the country had enough knowledge of the Internet, it decided to popularize it to the people. Now, this period is called the exploration growth period (19992005). At that time, the network did not have the same relationship as now. At that time, the Internet was very insensitive, almost no interaction, only web pages used to display information. Many Internet giants also began to rise from that time. When they have completed their exploration of the Internet, they are aware of its business routine. After that, the business model of the Internet was established very quickly. The website is no longer the leader of information, and gradually the individual has gradually become the main source of information. This stage is called the rapid development period (2005-2010). The next stage is the mature and prosperous period (2010-2021). This stage is the mature Internet stage we are currently experiencing. From the prevalence of microblog to the outbreak of mobile Internet in 2012, mobile applications and message flow social networks coexist, which truly reflects the commercial value of the Internet and presents an unprecedented prosperity. Since then, since 2008, since the launch of smart phones, related technologies have been advancing rapidly. Alibaba has launched Alipay and other related technologies, so that people do not need to carry mobile phone with mobile phone. This is also the credit of QR code. Similarly, in 2010, Taobao and other online shopping services developed rapidly and became the progress of the Internet. People can buy their favourite things online without going out. ${ }^{[3-4]}$

\section{COMPARISON OF AGRICULTURAL DEVELOPMENT BETWEEN CHINA AND THE UNITED STATE}

\subsection{History of agricultural development in China}

There are four stages in the development of Chinese agriculture: primitive agriculture, that is, the so-called 
Neolithic age, people began to use a series of tools: slash and burn, marking the transition of ancient human lifestyle from collection to planting. Since then, people have experienced extensive agriculture and ancient agriculture. People have improved a series of planting methods, such as water conservancy projects and agricultural tools, such as bobbins. When people developed modern agriculture (1840-1949), things began to become different, the Opium War began, foreign powers began to invade China, which made China's ancient agricultural model begin to become different. The intensive agricultural model and the industrialization model began to meet and collide in 1840. Finally, China's traditional agricultural model of self-sufficiency began to disintegrate gradually. ${ }^{[5]}$

In modern agriculture, the Tian $\mathrm{Mu}$ system of the Chinese dynasty was put forward, but in the end, it did not come to an end, because it was the absolute equalitarianism of farmers, but this scheme could not move forward the social productivity, and finally the system was "bankrupt".

The second is the average land ownership. The government increases the tax levied on the land, so as to eliminate the possibility that the landlord can make huge profits from the address and land price. Moreover, it further puts forward that "if farmers lack land and become tenants, the state should give land" and hopes that every farmer without land will be forced to become a farmer who works as a landlord and has land to grow. However, this bill does not help farmers much, especially when the revolution rises, low prices cannot rise, farmers are still oppressed by landlords, and farmers will not reform, which is also one of the reasons for the failure of the reform. So far, modern agriculture has also reached the last stage of the agrarian revolution. After the end of World War II, the Communist Party put agricultural production first, gave land to the poor peasants, suppressed the rich peasants and the landlord class, and agricultural production has been vigorously developed. After a series of reforms, China's agricultural development. But so far, China has entered a dark period, the era of the great leap forward, and the main mistakes of high indicators, blind command and boasting are seriously rampant. The great leap forward era has seriously damaged the interests of farmers and affected their enthusiasm. Agricultural production has been greatly damaged and agricultural output has stagnated for a long time. Finally, the household contract responsibility system helped the country achieve a bumper grain harvest. ${ }^{[2]}$

In modern agriculture, machines are gradually used in agriculture: most of the work in this period was still human, but machines gradually replaced human beings, sowing, watering and so on. The agricultural model has gradually changed. It is no longer produced and sold by itself. Through the combination with the Internet, a new agricultural model has been developed. Subsequently, China's e-commerce gradually became the mainstream business model in China. ${ }^{[6-7]}$

However, e-commerce is not as easy as people think. It can't make a lot of money. There are also disadvantages: when e-commerce involves food, everyone will complain that they can't protect the freshness of food. Because it can't be kept fresh in time due to the road. Moreover, on the Internet, there are many businesses whose physical objects are inconsistent with the photos, which are ignored after being complained, and many express will make the express pile up. Make residents feel uncomfortable. But ecommerce is also beneficial. It makes people's life more convenient. In the past, if people needed to shop, they could only buy goods locally. However, with ecommerce, people can choose their favourite goods from all over the country and choose to deliver them to the door, so that people can have a better shopping experience. ${ }^{[8]}$

\subsection{American agricultural development history}

Since the independence of the United States, the government has attached great importance to the development of agriculture. In the early 1860s, the agricultural model changed from the manual era to the transition of semi mechanization. At that time, science and technology had not developed to full mechanization, but semi mechanization also helped the development of American agriculture to a great extent, which not only increased American agricultural output, but also liberated a lot of human labour, so that these labour can help other fields. By the 1950s, American agriculture had been mechanized. So far, agricultural production began to surge. After the 1980s, American agriculture has realized comprehensive modernization. In this process, the U.S. government has played an important role. Helping regulation is the fundamental guarantee for the health of American agriculture. In the United States from 2000 to 2021, the contribution rate of science and technology has reached $70 \%$, and the agricultural system of the United States is constantly extending and completing the agricultural industrial system, which also promotes the upgrading of the agricultural industry. From the end of the 19th century to the eve of the first World War. Because the vast wasteland reclaimed in the west is fertile land, a better harvest can be obtained without great effort. In this way, the growth of agricultural products exceeds the growth rate of market demand, resulting in a surplus of agricultural products and a decline in the price of agricultural products. The agricultural crisis has dealt a serious blow to agriculture in the eastern United States. Due to the small scale of farms in the East, poor land fertility and lack of competitiveness compared with the west, industrial and agricultural crises occurred at the 
same time during this period. The main reason is that the agricultural production of belligerent countries after World War I was gradually restored and developed, which not only reduced Ding's purchase of American agricultural products, but also competed with the United States in the international market, greatly reducing the export of American agricultural products, Farm income fell sharply, and many small farms went bankrupt. It was not until the outbreak of World War II that American agriculture entered a new prosperity. The reason for this problem is the intensification of the contradiction between the wartime expanded productivity and the post-war shrinking sales market. This problem lasts for a long time and does serious harm. The main manifestations are as follows: 1. Many agricultural products are accumulated. Except for the war of aggression against Korea and the war of aggression against Vietnam, other years increased almost every year, which continued until the early 1970s. During this period, the largest accumulation was grain. 2. The price of agricultural products fell and the scissors gap between industry and agriculture expanded. 3. The farm income has declined, and small and medium-sized farmers have gone bankrupt one after another. 1981-1982 foreign cheap agricultural products also caused an impact on American agriculture. Due to the international economic recession and the appreciation of the US dollar, it is increasingly difficult to export agricultural products, and low-priced agricultural products flow back to the United States. Many overseas markets have been taken away by Canada, Brazil and other countries. ${ }^{[9-10]}$

\section{INTERNET PLUS AGRICULTURE MODE}

\section{1. agricultural product brand Entrepreneurship Model}

Nowadays, people use e-commerce to buy something that is not common in their area, but there is no accurate index in the purchase process. People don't know which kind to buy. In addition, farmers don't give explanations. This leads to people's experience in the purchase process is not very good, thinking that there is no accurate index or brand for customers to choose. This series of problems prompted the birth of agricultural product brand entrepreneurship model. The purpose of its birth is to ensure that customers have a better experience in the purchase process, because after creating a brand, people will be more inclined to buy branded agricultural products. And after the brand has established its image, people will recommend products to others. People have more power to follow the brand, but it's not just about this. Similarly, there is a bad side. Broken or rotten goods will inevitably be encountered in this brand, and this is the brand, which makes people remember that the agricultural products purchased by this brand next time will try to avoid buying the products of this brand. Moreover, during transportation, the product cannot guarantee the freshness of food, resulting in a decline in people's impression of the product. The strategy is to try to make agricultural products that can be preserved for a long time, such as nut shell food such as walnuts.

\section{2.rural e-commerce}

In the past, farmers' agricultural products were mainly produced and sold by themselves. If there were rich people, they would sell them. But in modern times, people in big cities don't grow food, which leads to a greater demand for agricultural products in rural areas. However, the road from rural to urban leads to the disconnection between the two. This prompted the birth of e-commerce. Through the e-commerce platform, people can put agricultural products online for trading. This has greatly promoted the development of rural agriculture and attracted young talents to rural construction. However, this is not only good, but also troublesome. Farmers are all agricultural products with a short shelf life, so agricultural products may become rotten during the mail process, which will lead to the decline of the reputation of e-commerce, and gradually no one may buy them again. Moreover, if too many people buy, a rural area cannot give too much labour force, because most of them are middle-aged people. All the young people in the village have gone out to work. This may lead to the collapse of this system.

\section{3.agricultural crowdfunding model}

Agricultural crowdfunding can run through all links of the whole agricultural chain, from agricultural breeding and planting to production, processing and sales. At the same time, if you can use the big data of the Internet to understand the needs of consumers in advance, you can organize production in an orderly manner. Start from the field, irrigate crops through Internet technology, and finally output qualified products, and then transmit them through the Internet. For consumers, food safety traceability system is very attractive. The demand for big data may not meet everyone's requirements, so this model meets the needs of a very small number of people to a great extent. At the same time, it meets the public's hobbies through big data. However, there are also disadvantages. Collision is not inevitable during transportation, which may make people dissatisfied with the customized levelling, and the final transportation process may destroy the whole intact system,

\section{CONCLUSION}

Internet plus agriculture has a trend which cannot be halted in the past ten years. China led Internet plus 
Internet plus agriculture policy. The policy of Internet and Internet plus has brought about rapid development opportunities for all countries and promoted the rapid development of agriculture led by China. However, since the global financial crisis in 2008 , the economy has been hit, which is associated with the continuous stagnation of agriculture; The slowdown of China's agricultural growth rate in recent ten years partly comes from the sluggish global economy, but also from the imbalance of China's demand structure, industrial structure and regional structure.Various domestic and international problems need to be solved, and new models need to be sought. An in-depth study of the significance and implementation effect of the policy can not only enrich the existing literature and research results, but also help to analyse the rationality of the current policy and put forward effective, targeted and feasible improvement measures in time.

\section{REFERENCES}

[1] Jiang Heping, song Lili. "Modern agricultural model in the United States." China Science and technology investment 09 (2008): 78-80.

[2] Feng Jikang. "American Agricultural Subsidy Policy: historical evolution and development trend." China's rural economy 000.003 (2007): 7378.

[3] Gu Wuhao. "Historic changes in China's agriculture." Shanghai collective economy 5 (2016): 20-25.

[4] Kou Guangtao, Lu Fengjun. "Internet plus agricultural industry chain" practice summary and innovation path. "Rural economy 8 issue (2016): 30-34.

[5] Hu Yongzhou. "Building Internet plus agriculture" intelligent production mode. "Shanghai rural economy 0.008 (2015): 37-38.

[6] Chen Jiangong, Li Xiaodong. "Historical stage division of China's Internet development." Internet world 000.003 (2014): 6-14.

[7] Wei Liurong, Wang Qi, LV Tingjie. "The development of Internet Interconnection in the United States and Its Enlightenment to China." World Telecom 018.005 (2005): 15-19.

[8] Wang Xu. "History of Internet development." personal computer 03 (2007): 182-188.

[9] Zhong Fengying, Na Xin, Wang Yu Wei. Innovative research on the Internet plus mode of agricultural development [J]. business economy, 2021 (07): 119-122.
[10] Ma Di, Han. "Internet plus" background of agricultural extension mode research $[\mathrm{J}]$. rural staff, 2021 (13): 21-22. 